\title{
Knowledge and attitudes of driver license applicants and instructors about driving of patients with epilepsy in Burkina Faso
}

\author{
Dabilgou Alfred Anselme ${ }^{1 *}$, Dravé Alassane ${ }^{2}$, Kyelem Julie Marie Adeline ${ }^{1}$, Eklou Lorrainda Emérance ${ }^{1}$, \\ Napon Christian ${ }^{3}$, Millogo Athanase ${ }^{4}$, Karfo Kapouni $^{5}$ and Kaboré Jean ${ }^{1}$
}

\begin{abstract}
Background: Epilepsy is the most common neurological disease in the world. The objective of the study was to determine the knowledge, attitude and practice of driver's license applicants and instructors in driving schools on epilepsy in Burkina Faso.

Method: This cross-sectional study was carried out from January 7th to March 7th 2020 in 21 driving schools approved by the National Driver License Authority in the city of Ouagadougou. Fifteen driver applicants and one instructor were selected in each driving school, resulting in a total of 315 driver applicants and 21 instructors in the study.

Results: The mean age of participants was $29.91 \pm 7.63$ years. One of the driver applicants included in the study was once experienced a seizure attack. All respondents had heard of epilepsy. The main source of epilepsy information was from family (42.5\%). Two hundred and twenty-six respondents (67.3\%) had witnessed an epileptic seizure. A majority of participants (55.9\%) believed that persons with epilepsy be not permitted to drive a motor vehicle. About $44.0 \%$ of participants thought that people with epilepsy should be permitted to drive under certain conditions. One hundred and four (30.9\%) participants suggested that people with epilepsy be permitted to drive a light vehicle. One hundred and forty-one (42.0\%) suggest to withdraw the driving license for lifetime if a driver had an epileptic seizure attack; while twenty-three (6.8\%) participants recommended suspension of driver license for 12 months.
\end{abstract}

Conclusion: Efforts should be made to improve awareness and education among license applicants and instructors on the driving by people with epilepsy.

Keywords: Knowledge, Driving by people with epilepsy, Driver license applicants, Burkina Faso

\section{Background}

Epilepsy is the most common neurological disease in the world with an estimated average prevalence of $8 \%$ worldwide and $80 \%$ of cases are in developing countries [1]. Epileptic seizures can be associated with impaired awareness and uncontrolled motor activity, which affect

*Correspondence: dabilgouanselm@yahoo.fr

${ }^{1}$ Department of Neurology, University Hospital Yalgado Ouedraogo, Ouagadougou, Burkina Faso

Full list of author information is available at the end of the article the ability to drive safely, and also impose a risk of bicycle, motorcycle, or pedestrian accidents [2,3]. Restrictions for motor vehicle driving have been imposed on individuals with epilepsy in many countries, yet with varied restrictions in detail, which can severely affect the everyday life [4]. Research on seizures and driving has highlighted a need for cooperation between driving authorities and doctors for further amendment of regulations and a reduction in the stigma attached to driving with epilepsy [5]. In Africa Sub-Saharan, driving a car is a 
privilege, and private car use is only gaining momentum with the arrival of cheaper second-hand vehicles from the Europe. So driving is yet to be a concern of people with epilepsy, health workers or driving license authority. Currently, there are no specific laws prohibiting people with epilepsy from driving in a majority of the countries. However, scientific research on the topic of "epilepsy and driving" is rather limited. In Burkina Faso, according to current road traffic rules for motor vehicle driving, individuals with epilepsy are allowed to drive. People with epilepsy are thus exposed to risks of serious road accidents due to possible seizure attacks during driving. In this context, all road users, including epileptic individuals, must be informed about the rules of driving, particularly in the event of epileptic seizures. This study was set out to survey on the knowledge of driver applicants and instructors on the driving of people with epilepsy, in order to understand the public attitude toward patient driving and provide guidance for public education and making driving-associated regulations.

\section{Methods}

\section{Study profile}

This cross-sectional study was carried out in driving schools in Ouagadougou City during January 7th and March 7th, 2020.

\section{Location of the study}

Burkina Faso is a francophone country located in the heart of West Africa. It covers an area of $274,200 \mathrm{~km}^{2}$ with an estimated population of 16,248,558 in 2006 according to the general population census. It is bounded to the north and west by Mali, to the south by Togo and Ghana, to the southeast by Benin, to the southwest by the Ivory Coast, and to the east by Niger. According to the administrative organization, Burkina Faso can be divided into 13 regions, 45 provinces, around 351 communes and 8000 villages. Ouagadougou and Bobo Dioulasso are two largest cities in the country with a highly dense population. Currently, the health care supply is insufficient in the country. The average ratio is one doctor per 22,017 inhabitants, one state nurse per 4000 inhabitants and a midwife for 14,000 inhabitants for all the country. The overall death rate is $11.8 \%$ and the life expectancy at birth is 56.7 years. The city of Ouagadougou, the administrative and political capital of the country, has an area of $21,500 \mathrm{~km}^{2}$ with an estimated population of 3 million in 2019.

\section{Public transportation and private driving pattern}

According to the statistics of the Ministry of Transport and Urban Mobility of Burkina Faso, the number of motor vehicles registered in 2017 was 30,914 and that of two-wheeled vehicles 278,324 [6]. Meanwhile, $60 \%$ of urban trips were made with two-wheeled vehicles which are not subject to any technical control, and then comes followed by trips by walking. The weakness of public transport has resulted in a huge number of private transportations. As a result, there were 19,881 recorded road accidents in 2017, causing 964 deaths [6].

\section{Driver license authority in Burkina Faso}

The National Driver License Authority is responsible for the general direction of land and sea transport, which regulates, plans and controls the implementation of the policy of the department with regard to land, sea and river transport. It is also responsible for the production of transport tickets, the establishment and issuance of transport authorizations (transport cards), registration certificates (gray cards) and driving licenses. Driving schools provide theoretical instruction in the highway code and practical teaching of driving for applicants for driving licenses, to help them get a driving license. The driving rules and safety are taught during the theoretical and practical period.

\section{Driving license regulations}

In Burkina Faso, when a person applies for a driving license, he or she must have undergone a course on the highway code and motor vehicle driving provided by a center or a driving school. In addition, he or she must possess good physical and mental health and be in a good physical and mental condition to drive. After obtaining a driving license, a competent doctor may issue a medical certificate of fitness, which mentions, where applicable, the obligation to wear corrective lenses or prosthetic devices. If the medical examiner concludes that the candidate is unfit, the vehicle driving license is refused or cancelled. The candidate may, however, request to be examined by an appeal committee appointed by the minister in charge of health. The suspension and provisional withdrawal, the cancellation and the final withdrawal of the driving license are pronounced after the opinion of the special technical commission for the withdrawal of driving licenses. The composition, powers and operation of this commission are specified by the authority regulator. The different driving licenses available in Burkina Faso are shown in Table 1. According to the statistics from Burkina Faso's Ministry of Transport, Urban Mobility, and Road Safety, in 2017 35,319 people were admitted with driving licenses in Ouagadougou and Bobo Dioulasso, of which the issued A1BC license had the highest proportion (91\%) [6]. 
Table 1 Types of driving license in Burkina Faso

\begin{tabular}{ll}
\hline Type of licence & Description \\
\hline A1 & License for light motorcycles with a displacement limited to $125 \mathrm{~cm}^{3}$ and a maximum power of $11 \mathrm{~kW}$. \\
A progressif & License for motorcycles whose power does not exceed $25 \mathrm{~kW}$. \\
B & License for motor vehicles with a permissible gross vehicle weight (GVWR) not exceeding $3.5 \mathrm{t}$, used for transporting people. \\
B1 & $\begin{array}{l}\text { License for motor tricycles, power less than or equal to } 15 \mathrm{~kW} \text {, and weight less than or equal to } 550 \mathrm{~kg} \text {; heavy motor quadricycles and } \\
\text { quads. }\end{array}$ \\
L & $\begin{array}{l}\text { License for isolated motor vehicles other than those in category D, with authorized gross vehicle weight (GVWR) exceeding 3.5t. } \\
\text { more than eight (8) people not including the driver. }\end{array}$ \\
E & License for trailers and caravans \\
$\mathrm{F}$ & License for people with motor disabilities of at least one upper and lower limb.
\end{tabular}

\section{Study population}

All driver license applicants and instructors were included in this study.

\section{Sample size}

We first selected one quarter of driving schools approved by the regulatory authority, then selected in each driving school 15 applicants and one instructor. During the study period, 84 driving schools were approved by the national driving license authority, so the number of driving schools included in the survey was 21 , comprising 315 applicants and 21 instructors.

\section{Pre-test}

A driving school was then selected for a pre-test to better assess the acceptability of the study among respondents, to assess their ability to respond and, above all, their interest in the study. The participants of the pre-test and the driving school were not included in the analysis of results.

\section{Sampling}

The 21 driving schools were chosen randomly from the approved list of driving schools. After establishing the passage order of all the driving schools, the study can began in the first driving school. The study objectives were presented to license applicants and instructors on the survey day, during a driving course. Then, the driver license applicants and instructors were invited to complete a questionnaire separately.

\section{Data collection and analysis}

The survey was conducted individually by interview. The survey sheet included questions on sociodemographic data (sex, age, level of study, socio-professional activity, residence), epilepsy (whether having heard of epilepsy, source of epilepsy information, whether having witnessed a seizure, whether having epilepsy, sources of information concerning interactions between epilepsy and driving), knowledge of interaction between epilepsy and driving, and attitude toward driver licensing to people with epilepsy (give a driver license or not, type of driver license, duration of restriction when a driver presents with a seizure). The data were analyzed using Epi Info version 7.

\section{Results}

Sociodemographic characteristics

The participants aged 29.91 \pm 7.63 years (ranging 18 to 60 years, $29.90 \pm 7.7$ years for applicants and $30.19 \pm 6.5$ years for instructors). The majority of participants aged under 45 years $(92.8 \%)$ and were male (60.4\%). All the participants were residing in Ouagadougou, the City capital of Burkina Faso. The sociodemographic characteristics of participants are provided in Table 2.

\section{Knowledge on driving by persons with epilepsy}

All respondents had heard of epilepsy. The main source of epilepsy information was from family (42.5\%), and $226(67.3 \%)$ respondents had already witnessed an epileptic seizure. A candidate said he had epilepsy with uncontrolled seizures. All of the applicants had driven motorbikes before applying a driving license. A majority of them $(90.5 \%)$ did not receive any drive information for people with epilepsy from the driving schools. The vast majority of instructors $(81 \%)$ said that they were not receiving direction from the regulator. A large proportion of applicants $(91.7 \%)$ said that they were not asked about the presence or a history of epileptic seizures by doctors.

\section{Attitudes toward driving by persons with epilepsy}

A majority (97.8\%) of applicants thought that epilepsy could be a cause of traffic road accidents. All of the instructors thought that epilepsy could not be the cause of traffic road accidents. About $25.3 \%$ of participants thought that epilepsy could be a consequence of traffic 
Table 2 Sociodemographic characteristics of study participants

\begin{tabular}{lll}
\hline Variable & $\begin{array}{l}\text { Population study } \\
(\boldsymbol{n = 3 3 6 )}\end{array}$ & Percentage (\%) \\
\hline $\begin{array}{ll}\text { Mean age (years) } \\
\text { Age group (years) }\end{array}$ & $29.91 \pm 7.63$ \\
$\quad<25$ & 75 & 22.3 \\
$25-44$ & 237 & 70.5 \\
$>45$ & 24 & 7.1 \\
Sex & & \\
Male & 203 & 60.4 \\
$\quad$ Female & 133 & 39.6 \\
Profession & & \\
Official & 150 & 44.6 \\
Students & 120 & 35.7 \\
Housewives & 18 & 5.3 \\
Seller & 48 & 14.3 \\
Educationnal level & & \\
None & 3 & 0.9 \\
Primary & 42 & 12.5 \\
Secondary & 118 & 13.1 \\
University & 173 & 51.5 \\
\hline
\end{tabular}

road accidents. With regard to the attitude toward driving by people with epilepsy, the majority of participants (188; 55.9\%) believed that people with epilepsy should not be permitted to drive a car or a motorbike. About $44.0 \%$ of the participants thought that people with epilepsy should be permitted to drive if they had infrequent attacks $(7.7 \%)$, if the treatment was well followed (34.2\%) and if the person with epilepsy is always accompanied (2.1\%). People with epilepsy should be permitted to drive a light vehicle $(104 ; 30.9 \%)$, a heavy vehicle $(8.6 \%)$, or a caravan or trailer $(8 ; 2.4 \%)$. The majority $(57.7 \%)$ of participants thought that the driving license should be suspended for lifetime (42\%), 12 months (3.6\%), 6 months (5.3\%) and 3 months (6.8\%), if a driver with epilepsy experienced a seizure attack during driving. Table 3 summarizes the responses of participants to questions involving epilepsy and driving $(n=336)$.

\section{Discussion}

In this study, we surveyed driving license applicants and instructors in driving schools to understand their knowledge and attitude toward driving by persons with epilepsy in an African country Burkina Faso. The level of information of participants on epilepy was high $(100 \%)$ and identical to that encountered in the study by Maiga in Mali [7]. This situation is explained by the fact that they all resided in the city where they have the opportunity to access the media and the Internet. Moreover, more than half of the participants (51.5\%) had a university level which predispose them to a good understanding of information. The proportion of participants having already witness an epileptic seizure was high (67.3\%), comparable to that found in previous community based studies in Ethiopia (79.7\%) [8] and in Nigeria (83.8\%) [9].

Despite this high level of familiarity of epilepsy, the majority of the driving license applicants $(90.5 \%)$ did not receive any information about driving by people with epilepsy from driving schools. In addition, the majority of the instructors $(81 \%)$ said they had not received any instruction from the regulatory department. These data suggest limited access to information for instructors and license applicants. As the number of instructors is limited per driving school, the instructors do not have enough to provide, in addition to teaching the highway code, and learning to drive, other lessons on driving regulations. The regulatory authority should ensure that regulations regarding the conduct of people with epilepsy are taught in driving schools. In addition, none of the license applicants in this survey were inquired by a doctor whether or not they had a history of epilepsy. This may be associated with the lack of awareness of doctors and candidates. Indeed, the medical file for a driving license does not contain any items that assess their neurological capacities to drive safely. In addition, this visit is carried out by physicians who do not specialize in epileptology (neurologists, neurosurgeons and psychiatricts). According to the international surveys, physicians are often ignorant of the guidelines regarding epilepsy and driving $[10,11]$. In addition, compared with neurologists, non-specialist physicians have been reported to hold restrictive beliefs about driving by individuals with epilepsy [12]. This situation could be avoided if the candidates declared their epileptic history to the doctor. A majority of patients with a diagnosis of epilepsy chose to hide this diagnosis during evaluation for a driving license in order to obtain the driving license $[13,14]$. Therefore, physicians should increase their awareness of finding a history of epileptic seizures and of referring any driver with a history of unconsciousness to a neurologist. In this study, we also assessed the knowledge of candidates and instructors on the interactions between epilepsy and road accidents.

Our study showed a lack of knowledge of all participants $(25.3 \%)$ on whether road accidents lead to epilepsy. All the instructors had a bad knowledge in identifying epilepsy as a probable cause of road accidents. These various shortcomings could be overcome by a good campaign of awareness about epilepsy and driving. In addition, all of the applicants, including a patient with uncontrolled seizures, had driven motorbikes before applying a driving license, representing a risk of traffic accidents on the public highway. Furthermore, a small proportion (25.3\%) of the participants had knowledge that road accidents 
Table 3 Participants responses about epilepsy and driving $(n=336)$

\begin{tabular}{|c|c|c|c|}
\hline Items & Study population $(n=336)$ & Applicants $(n=315)$ & Instructors $(n=21)$ \\
\hline \multicolumn{4}{|c|}{ 1. Is epilepsy the cause of road accidents? } \\
\hline Yes & $308(91.7 \%)$ & $308(97.8 \%)$ & 0 \\
\hline No & $22(6.5 \%)$ & $1(0.3 \%)$ & $21(100 \%)$ \\
\hline Don't known & $6(1.8 \%)$ & $6(1.9 \%)$ & 0 \\
\hline \multicolumn{4}{|l|}{ 2. Can road accidents lead to epilepsy? } \\
\hline Yes & $85(25.3 \%)$ & $83(26.3 \%)$ & $2(9.5 \%)$ \\
\hline No & $212(63.1 \%)$ & $197(62.5 \%)$ & $15(71.4 \%)$ \\
\hline Don't known & $39(11.6 \%)$ & $35(11.1 \%)$ & $4(19 \%)$ \\
\hline \multicolumn{4}{|l|}{ 3. Is epilepsy taught in driving school? } \\
\hline Yes & $24(7.1 \%)$ & $20(6.3 \%)$ & $4(19 \%)$ \\
\hline No & $302(89.9 \%)$ & $285(90.5 \%)$ & $17(81 \%)$ \\
\hline Don't known & $10(3 \%)$ & $10(3.2 \%)$ & 0 \\
\hline \multicolumn{4}{|c|}{ 4. Is epilepsy discussed at the medical examination? } \\
\hline Yes & $28(8.3 \%)$ & $26(8.2 \%)$ & $2(9.5 \%)$ \\
\hline No & $308(91.7 \%)$ & $289(91.7 \%)$ & $19(90.5 \%)$ \\
\hline \multicolumn{4}{|c|}{ 5. Should a driver's license be issued to an epileptic? } \\
\hline Yes & $148(44.0 \%)$ & $143(45.4 \%)$ & $5(23.8 \%)$ \\
\hline No & $188(55.9 \%)$ & $172(54.6 \%)$ & $16(76.2 \%)$ \\
\hline \multicolumn{4}{|c|}{ 5.1. Under what conditions will you issue the permit? } \\
\hline Yes, if attacks are not frequent & $26(7.7 \%)$ & $25(7.9 \%)$ & $1(4.8 \%)$ \\
\hline Yes, if treatment is well followed & $115(34.2 \%)$ & $111(35.2 \%)$ & $4(19 \%)$ \\
\hline Yes, if driver is always accompanied & $7(2.1 \%)$ & $7(2.2 \%)$ & 0 \\
\hline No & $188(56.0 \%)$ & $172(54.6 \%)$ & $16(76.2 \%)$ \\
\hline \multicolumn{4}{|c|}{ 6. Type of license to be issued to epilepsy } \\
\hline None & $188(56.0 \%)$ & $172(54.6 \%)$ & $16(76.2 \%)$ \\
\hline Moped & $7(2.1 \%)$ & $5(1.6 \%)$ & $2(9.5 \%)$ \\
\hline Light vehicle & $104(30.9 \%)$ & $102(32.4 \%)$ & $2(9.5 \%)$ \\
\hline Heavy vehicle & $29(8.6 \%)$ & $28(8.9 \%)$ & $1(4.8 \%)$ \\
\hline Caravan vehicle & $8(2.4 \%)$ & $8(2.5 \%)$ & 0 \\
\hline \multicolumn{4}{|l|}{ 7. Driving restriction } \\
\hline For lifetime & $141(42.0 \%)$ & 129 (40.9\%) & $12(57.1 \%)$ \\
\hline 3 months & $23(6.8 \%)$ & $10(3.2 \%)$ & $2(9.5 \%)$ \\
\hline 6 months & $18(5.3 \%)$ & $17(5.4 \%)$ & $1(4.8 \%)$ \\
\hline 12 months & $12(3.6 \%)$ & $21(6.7 \%)$ & $2(9.5 \%)$ \\
\hline None & $142(42.3 \%)$ & $138(43.8 \%)$ & $4(19.0 \%)$ \\
\hline
\end{tabular}

could be complicated by epileptic seizures, unlike the study by Maiga in Mali (60\%) [7]. This discrepancy could be explained by the socio-demographic characteristics of the participants, the size of the sample, and the experiences of participants about driving by people with epilepsy. Regarding the rules for granting a driving license, the majority of participants (55.9\%) believed that patients with epilepsy be not permitted to drive an automobile, consistent with a similar study in Mali (86.4\%) [7] and a community-based study in Saudi Arabia (60\%) [15]. Only a small proportion of participants (44\%) thought that people with epilepsy could be permitted to drive under conditions that they had infrequent attacks (7.7\%), the treatment was well followed (34.2\%) and the person with epilepsy is always accompanied (2.1\%). As seizure attacks are unpredictable, the driver, even accompanied, is exposed to serious traffic accidents even when there is less seizures. The expert opinion and guidelines regarding fitness to drive vary among countries and even states [16-21]. The vast majority of countries in the world allow people with epilepsy to drive if they have been seizurefree for a long period and possess physical fitness [21]. According to the driver license type, the participants in this survey considered that people with epilepsy should 
be permitted to drive a light vehicle (30.9\%), a heavy vehicle $(8.6 \%)$, or a caravan or trailer $(2.4 \%)$. This is consistent with a previous study by Maiga in Mali, which reported proportions of $13.3 \%$ for light vehicle license and $0.4 \%$ for heavy vehicle license [9]. If a driver with epilepsy has a seizure attack during driving, the majority of the participants (57.7\%) suggested to suspend the driver's license. A better solution is to leave it to a neurologist who will then determine the suspension duration of the driver's license. Only $6.8 \%$ of the participants provided consistent answers on suspension duration with the austroads guidelines, which suggests that people who have had a crash or have lost control of the vehicle as a consequence of a seizure, should not be allowed to drive until after a 12-month seizure-free period (SFP) for private drivers and a 10-year SFP for commercial drivers [22]. Importantly, private drivers (driving a car, a motorcycle or a tractor) and commercial drivers (driving a bus or truck) who have epilepsy have a different set of restrictions based on different risk factors, depending on the time spent driving, the size of the vehicle being driven and the cargo being transported [20, 23-25]. Therefore, the Burkinabe National League against Epilepsy is recommended to implement a guideline on this issue.

\section{Strengths and limitations of the study}

This cross-sectional study employed a significant number of participants with a sufficient education level to answer questions, of whom $51.5 \%$ had a university level. This study also had some limitations. The small number of instructors included in the study may induce a bias into the answers to some questions. Because of the small number of instructors, we did not analyze the factors contributing to the better knowledge of applicants and instructors on driving by people with epilepsy.

\section{Conclusion}

Our study revealed that the participants did not have adequate access to information on epilepsy and driving licenses. Legislations on driving by people with epilepsy based on the international regulations are needed in this country.

\section{Abbreviation \\ SFP: Seizure-free period.}

\section{Acknowledgments}

The authors wish to thank all the participants of this study, all driving schools, and the National Driving License Authority of Burkina Faso.

\section{Authors' contributions}

DAA, DA, KJMA and EL participated in the writing and editing of this manuscript. NC, MA, KK, and KJ contributed to the concept and the design of this manuscript. The author(s) read and approved the final manuscript.
Funding

Not applicable.

Availability of data and materials

The data are available from the corresponding author.

\section{Declarations}

\section{Ethics approval and consent to participate}

This study was approved by the local Ethic Committee of Medical School of Joseph Ki Zerbo University. We had authorization of Driver License Authority of Burkina Faso to conduct the study in driving schools. All the participants had given their informed consent before the survey. All the driving schools included in this study were approved by the Driver License Authority. The privacy of the participants and the confidentiality of the data collected have been complied with.

\section{Consent for publication}

The participant's verbal consent at enrolment has been obtained.

\section{Competing interests}

The authors declared that they had no competing interests.

\section{Author details}

${ }^{1}$ Department of Neurology, University Hospital Yalgado Ouedraogo, Ouagadougou, Burkina Faso. ${ }^{2}$ Department of Neurology, Regional University Hospital of Ouahigouya, Ouahigouya, Burkina Faso. ${ }^{3}$ Department of Neurology, University Hospital of Bogodogo, Ouagadougou, Burkina Faso. ${ }^{4}$ Department of Neurology, University Hospital of Sourou Sano, Bobo Dioulasso, Burkina Faso. ${ }^{5}$ Department of Psychiatry, University Hospital of Bogodogo, Ouagadougou, Burkina Faso.

Received: 5 November 2020 Accepted: 23 November 2021

Published online: 06 January 2022

\section{References}

1. World health organization, world federation of neurology, programme for neurological. Disease and Neuroscience Department of Mental Health and Substance Abuse. In: Atlas country resources for neurological disorders 2004, vol. 2004. Geneva: World Health Organization; 2004. p. 59.

2. Aschkenasy MT, Drescher MJ, Ratzan RM. Physician reporting of medically impaired drivers. J Emerg Med. 2006;30:29-39.

3. Van den Broek M, Beghi E, RESt-1 Group. Accidents in patients with epilepsy: types, circumstances, and complications: a European cohort study. Epilepsia. 2004;45:667-72.

4. McLachlan RS, Starreveld E, Lee MA. Impact of mandatory physician reporting on accident risk in epilepsy. Epilepsia. 2007:48:1500-5.

5. Inoue Y, Ito M, Kurihara M, Morimoto K. Epilepsy and driving in Japan. Epilepsia. 2004;45(12):1630-5.

6. Ministère des Transports, de la mobilité urbaine et de sécurité routière du Burkina Faso. Tableau de bord statistique 2017du secteur des transport; 2019. p. 89.

7. Maiga Y, Sidibe I, Napon C, et al. Epilepsy and driving licence in Mali: knowledge, attitudes and practices of driving schools monitors and the candidates for the licence. AJNS. 2013;32(2):3-8.

8. Wubetu AD, Basha EA, Engidaw NA. Public Knowledge and Attitude towards Epilepsy and Its Associated Factors: Community-Based CrossSectional Study, Ethiopia, 2019. J Environ Public Health. 2020. Article ID 6801979, 8 pages. https://doi.org/10.1155/2020/6801979.

9. Ezeala-Adikaibe BA, Achor JU, Nwabueze AC, Agomoh AO, Chikani M, Ekenze OS, et al. Knowledge, attitude and practice of epilepsy among community residents in Enugu, South East Nigeria. Seizure. 2014;23:882-8

10. Winston GP, Jaiser SR. Western driving regulations for unprovoked first seizures and epilepsy. Seizure. 2012;21:371376. 
11. Shanahan EM, Sladek RM, Phillips P. Medical aspects of fitness to drive. What do public hospital doctors know and think? Intern Med J. 2007;37:372-6.

12. Beran RG, Ainley LAE, Beran ME. Opinions, attitudes and practices of Australian neurologists with regard to epilepsy and driving. Internal Med J. 2007;37(4):251-7.

13. Elliott JO, Long L. Perceived risks, resources, and perceptions concerning driving and epilepsy: a patient perspective. Epilepsy Behav. 2008:13(2):381-6.

14. Tedrus GM, Fonseca LC, Oliveira EM, et al. Factors associated with the employment situation and driving license of patients with epilepsy. J Epilepsy Clin Neurophysiol. 2010;16(4):136-42.

15. Algahtani H, Shirah B, Shaheen M. Perception and attitude of general population towards epilepsy in Jeddah, Saudi Arabia. J Epilepsy Res. 2019;9(1):42-50.

16. Ooi WW, Gutrecht JA. International regulations for automobile driving and epilepsy. J Travel Med. 2000;7:1-4

17. Mintzer S. Driven to tears: epilepsy specialists and the automobile. Epilepsy Curr. 2015;15(5):279-82.

18. Baulac M. de BH, Elger C, Glynn M, et al. epilepsy priorities in Europe: a report of the ILAE-IBE epilepsy advocacy Europe task force. Epilepsia. 2015:56(11):1687-95.

19. Mahmud S, Hwang ST. Understanding variability in driving recommendations for patients with seizures. Epilepsy Behav. 2017;77:44-9.

20. Beghi E, Sander JW. Epilepsy and driving: regulations in the European Union need harmonization as well as greater flexibility. Br Med J. 2005;331:60-1.

21. Drazkowski J. An overview of epilepsy and driving. Epilepsia. 2007:48(Suppl 9):10-2.

22. Lloyd S. Assessing fitness to drive for commercial and private vehicle drivers (Medical Standards for Licensing and Clinical Management Guidelines-a resource for health professionals in Australia). 2012;472-473.

23. Beran RG. An analysis and overview of the guidelines for assessing fitness to drive for commercial and private vehicle drivers. Int Med J. 2005:35:364-8.

24. Hocking B, Landgren F. New medical standards for commercial and private drivers. MJA. 2003;179:276-7 4.

25. Hurley D. When epileptic patients crash: legal airbags protect most neurologists, but buckle your seat belt just the same. Neurol Today. 2007;7:18-9.

- fast, convenient online submission

- thorough peer review by experienced researchers in your field

- rapid publication on acceptance

- support for research data, including large and complex data types

- gold Open Access which fosters wider collaboration and increased citations

- maximum visibility for your research: over $100 \mathrm{M}$ website views per year

At BMC, research is always in progress.

Learn more biomedcentral.com/submissions 